\title{
A psychoeducational intervention reduces the need for anesthesia during radiotherapy for young childhood cancer patients Sonja Haeberli ${ }^{1}$, Michael A Grotzer ${ }^{1}$, Felix K Niggli ${ }^{1}$, Markus A Landolt ${ }^{2}$, Claudia Linsenmeier ${ }^{3}$, Roland A Ammann ${ }^{4}$ and Nicole Bodmer*1
}

\author{
Address: ${ }^{1}$ University Children's Hospital of Zurich, Department of Oncology, Steinwiesstr. 75, 8032 Zurich, Switzerland, ${ }^{2}$ University Children's \\ Hospital of Zurich, Department of Psychosomatics and Psychiatry, Steinwiesstrasse 75, Zurich, Switzerland, ${ }^{3}$ University Hospital Zurich, \\ Department of Radio-Oncology, Raemistr. 100, 8032 Zurich, Switzerland and ${ }^{4}$ University Children's Hospital of Berne, Division of Pediatric \\ Hematology-Oncology, Inselspital, 3010 Berne, Switzerland \\ Email: Sonja Haeberli - Sonja.Haeberli@gmx.net; Michael A Grotzer - Michael.Grotzer@kispi.uzh.ch; Felix K Niggli - Felix.Niggli@kispi.uzh.ch; \\ Markus A Landolt - Markus.Landolt@kispi.uzh.ch; Claudia Linsenmeier - Claudia.Linsenmeier@usz.ch; \\ Roland A Ammann - Roland.Ammann@insel.ch; Nicole Bodmer* - Nicole.Bodmer@kispi.uzh.ch \\ * Corresponding author
}

Published: 4 June 2008

Radiation Oncology 2008, 3:17 doi:10.1186/1748-7|7X-3-17

This article is available from: http://www.ro-journal.com/content/3/l/I7

(c) 2008 Haeberli et al; licensee BioMed Central Ltd.

This is an Open Access article distributed under the terms of the Creative Commons Attribution License (http://creativecommons.org/licenses/by/2.0), which permits unrestricted use, distribution, and reproduction in any medium, provided the original work is properly cited.

\begin{abstract}
Background: Radiotherapy (RT) has become an important treatment modality in pediatric oncology, but its delivery to young children with cancer is challenging and general anesthesia is often needed.

Methods: To evaluate whether a psychoeducational intervention might reduce the need for anesthesia, 223 consecutive pediatric cancer patients receiving 4I4I RT fractions during 244 RT courses between February 1989 and January 2006 were studied. Whereas in I54 RT courses corresponding with $2580 \mathrm{RT}$ fractions patients received no psychoeducational intervention (group A), 90 RT courses respectively I56I RT fractions were accomplished by using psychoeducational intervention (group B). This tailored psychoeducational intervention in group B included a play program and interactive support by a trained nurse according to age to get familiar with staff, equipment and procedure of radiotherapy.
\end{abstract}

Results: Group A did not differ significantly from group $B$ in age at RT, gender, diagnosis, localization of RT and positioning during RT. Whereas $33(21.4 \%)$ patients in group A got anesthesia, only $8(8.9 \%)$ patients in group $B$ needed anesthesia. The median age of cooperating patients without anesthesia decreased from 3.2 to 2.7 years. In both uni- and multivariate analyses the psychoeducational intervention significantly and independently reduced the need for anesthesia.

Conclusion: We conclude that a specifically tailored psychoeducational intervention is able to reduce the need for anesthesia in children undergoing RT for cancer. This results in lower costs and increased cooperation during RT. 


\section{Background}

In pediatric oncology, radiotherapy (RT) alone or in combination with surgery, has become an important treatment option for achieving local tumor control. However, administering RT to children requires a great deal of cooperation [1]. To facilitate RT, many hospitals routinely use sedation or general anesthesia for all young children $[2,3]$. This demands infrastructure and equipment and may also cause disturbances of daily routine, higher costs, and sideeffects in the child $[4,5]$. Interactive intervention concepts for performing invasive and non-invasive procedures without general anesthesia in children have already been designed for some procedures like magnetic resonance imaging, electroencephalography, or bone marrow aspiration [6-12] and are also increasingly applied in pediatric oncology. They include cognitive distraction, behavioral rehearsal, or multimodal intervention packages [13-16]. Some reports have also shown that interactive psychoeducational interventions can help children to cooperate for RT $[1,4,5,17,18]$. To our knowledge, however, no study included a direct comparison of supported and unsupported patients in the same institution. Therefore, the purpose of this study was to evaluate the efficacy of a targeted psychoeducational intervention program in decreasing the need for anesthesia in a large group of unselected pediatric oncology patients receiving RT.

\section{Methods}

A series of 223 pediatric cancer patients treated at the University Children's Hospital of Zurich who received RT between February 1989 and January 2006 was included in a retrospective study. These 223 patients underwent 244 RT courses with a total of 4141 RT fractions. Curative RT according to the treatment regimen (median 24 Gray, range 4.5-68 Gray), as well as palliative RT (median 21 Gray, range 4.5-50 Gray) for alleviation of pain were incorporated. Until February 1999, 154 RT courses corresponding to 2580 RT fractions were applied with routine care but without psychoeducational intervention. Since then, patients in $90 \mathrm{RT}$ courses corresponding to $1561 \mathrm{RT}$ fractions received an individually tailored psychoeducational intervention. The intervention consisted of talks with the patient and his family about practical aspects of the upcoming RT procedure and an age-based careful explanation and practice of the RT procedure. Aim of this multimodal support was an age-appropriate preparation for the procedure. Implementally, picture books explaining the procedure, playful inclusion of toys, and a reward systems using beads as tokens for every accomplished RT session were used $[17,19,20]$. Attendance at least for the preparing computer tomography, RT simulation and the first RT session as well as weekly visitations during the RT procedures was accomplished. This support before and during RT was always given by one of two specially trained nurses and required about $5-7.5$ hours per patient. On average, they met the patient five times. The procedure of planning and administering RT didn't differ from that of group A. If the patient didn't cooperate and the RT session was not feasible, a second attempt to accomplish RT without anesthesia was arranged. For still uncooperative patients anesthesia was used. This included general anesthesia or sedation by intravenous, rectal, or oral medication. Chloral hydrate $(50-80 \mathrm{mg} / \mathrm{kg}$, rectal administration) was the first choice for sedation.

The association of the psychoeducational intervention and of six predefined clinical variables with the need for anesthesia was analyzed using uni- and multivariate Poisson regression, with the number of RT fractions as rate multiplier. These clinical variables were time point and age at start of RT, sex, diagnostic group (CNS tumor, extracranial solid tumor, leukemia), localization of RT (head versus other localizations), and positioning during irradiation (supine versus other). For multivariate analysis, stepwise forward variable selection was chosen. LogXact 6 software was used (Cytel Software Corp., Cambridge, MA, USA).

\section{Results}

Group A and B did not differ significantly in respect of sex, age, total dose and times of irradiation, diagnosis, site of irradiation and positioning, thus indicating that the two groups of patients are comparable from a clinical point of view. In total, anesthesia was needed in 41 (16.8\%) of 244 RT courses. This proportion was significantly lower in group B ( 8 of $90=8.9 \%$ ) than in group A ( 33 of $154=$ $21.4 \% ; P=0.015$, table 1$)$. This difference remained significant when corrected for several variables potentially associated with the need for anesthesia, including the year of RT as an indicator of changes in the environment (multivariate $P=0.018$; table 2 ). A sensitivity analysis regarding only the first RT course per patient fully confirmed these findings (multivariate odds ratio [OR], 0.74; 95\% confidence interval $[\mathrm{CI}], 0.57-0.97 ; P=0.027)$.

The psychoeducational intervention reduced the median age of patients needing anesthesia from 3.2 (range 0.0 12.0 ) to 2.7 (range 1.6 - 4.3) years (Figure 1; OR for children below 5 years of age, $0.37 ; 95 \%$ CI, 0.29-0.47; $P<$ $0.001)$. Overall, more girls needed anesthesia than boys (18/80 girls vs. $23 / 164$ boys). Interestingly, the support seemed to be more effective in girls than in boys, however; while without support $33.3 \%$ of all female patients needed anesthesia, the anesthesia rate could be reduced with support to only $3.4 \%$. In contrast, there was only a slight decrease of anesthesia in boys due to application of support: While $15.5 \%$ of all male patients without support needed anesthesia, the rate was still $11.5 \%$ with support. 
Table I: Clinical Characteristics of Group A (no intervention) and Group B (intervention)

\begin{tabular}{|c|c|c|c|c|c|}
\hline & \multicolumn{2}{|c|}{$\begin{array}{c}\text { Group A } \\
\text { No Intervention }\end{array}$} & \multicolumn{2}{|c|}{$\begin{array}{c}\text { Group B } \\
\text { Intervention }\end{array}$} & \multirow[t]{2}{*}{$P$} \\
\hline & $\mathbf{N}$ & (\%) & $\mathbf{N}$ & (\%) & \\
\hline Number of RT courses & 154 & $63.1 \%$ & 90 & $36.9 \%$ & \\
\hline Number of RT fractions & 2580 & $62.3 \%$ & $|56|$ & $37.7 \%$ & \\
\hline \multicolumn{6}{|l|}{ Sex } \\
\hline Male & 103 & $66.9 \%$ & 61 & $67.8 \%$ & \\
\hline Female & 51 & $33.1 \%$ & 29 & $32.2 \%$ & \\
\hline \multicolumn{6}{|l|}{ Age } \\
\hline Median & 7.9 & & 8.1 & & \\
\hline Mean & 9 & & 8.9 & & \\
\hline Range & $0.0-19.0$ & & $1.6-19.1$ & & \\
\hline \multicolumn{6}{|l|}{ Anesthesia } \\
\hline Yes & 33 & $21.4 \%$ & 8 & $8.9 \%$ & $p=0.015$ \\
\hline No & 121 & $78.6 \%$ & 82 & $91.1 \%$ & \\
\hline \multicolumn{6}{|c|}{ Age of those with anesthesia (Years) } \\
\hline Median & 3.2 & & 2.7 & & $p<0.001$ \\
\hline Mean & 3.2 & & 2.7 & & \\
\hline Range & $0.0-12.0$ & & $1.6-4.3$ & & \\
\hline Standard Deviation & 2.1 & & 0.9 & & \\
\hline \multicolumn{6}{|c|}{ Total dose of irradiation (Gray) } \\
\hline Median & 24.0 & & 20.0 & & \\
\hline Mean & 28.9 & & 31.2 & & \\
\hline Range * & $4.0-59.4$ & & $6.0-68.0$ & & \\
\hline Standard Deviation & 16.8 & & 19.0 & & \\
\hline \multicolumn{6}{|c|}{ Total times of irradiation } \\
\hline Median & 12.5 & & 12.0 & & \\
\hline Mean & 16.8 & & 17.3 & & \\
\hline Range & $1.0-54.0$ & & $3.0-36.0$ & & \\
\hline Standard Deviation & 10.3 & & 10.6 & & \\
\hline \multicolumn{6}{|l|}{ Diagnostic group } \\
\hline CNS tumor & 31 & $20.1 \%$ & 25 & $27.8 \%$ & \\
\hline Leukemia/Lymphoma & 67 & $43.5 \%$ & 43 & $47.8 \%$ & \\
\hline Solid tumor & 56 & $36.4 \%$ & 22 & $24.4 \%$ & \\
\hline \multicolumn{6}{|l|}{ Site of irradiation } \\
\hline Cranial irradiation & 98 & $63.6 \%$ & 56 & $62.2 \%$ & \\
\hline Extracranial irradiation & 56 & $36.4 \%$ & 34 & $37.8 \%$ & \\
\hline \multicolumn{6}{|l|}{ Positioning } \\
\hline Prone position & 19 & $12.3 \%$ & 19 & $21.1 \%$ & \\
\hline Supine position & 129 & $83.8 \%$ & 64 & $71.1 \%$ & \\
\hline Other position & 6 & $3.9 \%$ & 7 & $7.8 \%$ & \\
\hline \multicolumn{6}{|l|}{ Intent of Radiotherapy } \\
\hline Curative & 132 & $85.7 \%$ & 83 & $92.2 \%$ & \\
\hline Palliative & 22 & $14.3 \%$ & 7 & $7.8 \%$ & \\
\hline
\end{tabular}

Calculation of clinical characteristics is based on number of RT courses and not RT fractions.

In 6 patients in group $A$ and 4 patients in group $B$ low total irradiation dosages of 4 to 6 Gray were applied for pain reduction for palliative treatment, and 4.5 and 6 Gray in a curative setting in two infants with neuroblastoma in Group B.

The costs for our intervention during a RT course, including in median six hours caring by the qualified nurse and material costs, were on average 220 USD for each patient. The median costs for anesthesia during a RT course were estimated to be 4600 USD for an average of 11 sedations or narcosis per accomplished RT. Psychoeducational sup- port was offered to all patients of group B regardless their age and RT planning details. In considering the above mentioned costs for anesthesia the costs for group A were 151800 USD for 33 anesthesia procedures, corresponding to 985 USD per patient $(n=154)$. In group $B$ the costs for 8 procedures with anesthesia were 36800 USD and the 
Table 2: Results of Uni- and Multivariate Logistic Regression of Clinical Variables on Need of Anesthesia

\begin{tabular}{|c|c|c|c|c|}
\hline \multirow[b]{2}{*}{ Potential Predictor } & \multicolumn{2}{|c|}{ Univariate Poisson regression } & \multicolumn{2}{|c|}{ Multivariate Poisson regression } \\
\hline & Odds Ratio (95\% Cl) & $\mathbf{P}$ & Odds Ratio (95\% Cl) & $P$ \\
\hline Age (odds ratio per year) & $0.52(0.49$ to 0.54$)$ & $<0.001$ & $0.58(0.55$ to 0.62$)$ & $<0.001$ \\
\hline Gender & $0.53(0.26$ to 1.10$)$ & 0.090 & 0.81 (0.67 to 0.99$)$ & 0.039 \\
\hline \multicolumn{5}{|l|}{ Diagnostic group (reference: CNS tumor) } \\
\hline Leukemia & 33.7 (16.6 to 68.4$)$ & $<0.001$ & $18.6(9.1$ to 38.2$)$ & $<0.001$ \\
\hline Solid tumor & 36.8 (18.2 to 85.9$)$ & $<0.001$ & $17.0(8.1$ to 35.7$)$ & $<0.001$ \\
\hline Site of irradiation (head vs. others) & $0.83(0.68$ to 1.00$)$ & 0.049 & 1.35 (1.04 to 1.77$)$ & 0.027 \\
\hline Positioning (head vs. others) & 6.97 (4.58 to 10.60$)$ & $<0.001$ & - & NS \\
\hline Psychoeducational support & 0.37 (0.29 to 0.47$)$ & $<0.001$ & 0.74 (0.57 to 0.95$)$ & 0.018 \\
\hline Time of irradiation (odds ratio per year) & $0.91(0.89$ to 0.93$)$ & $<0.001$ & - & NS \\
\hline
\end{tabular}

NS indicates not significantly associated with need of anesthesia in multivariate analysis.
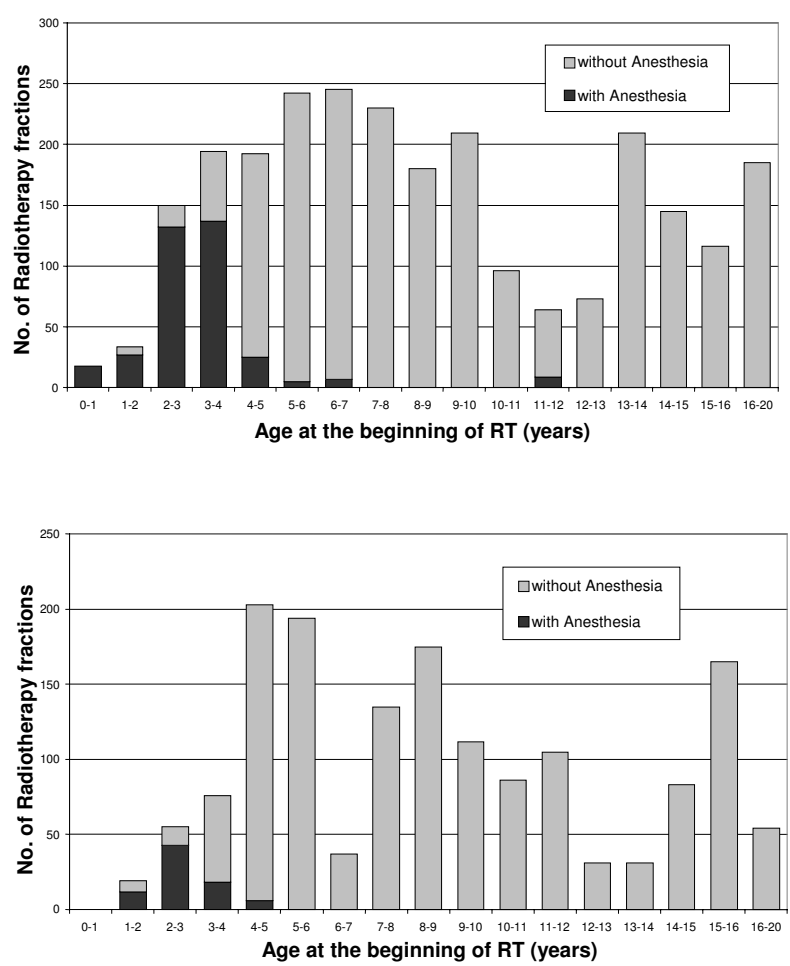

Figure I

Age distribution and need for anesthesia. Age at start of radiotherapy and need for anesthesia in 164 radiotherapy courses without $(A)$ and 90 courses with psychoeducational intervention (B). Black bar indicates RT with anesthesia, grey bar indicates RT without anesthesia.

costs for psychoeducational support for all 90 patients were 19800 USD, which means 630 USD per patient in group B. Therefore, the psychoeducational intervention reduced the costs by $36 \%$.

\section{Discussion}

In the current study, an individually tailored psychoeducational intervention was effective in reducing the need for anesthesia in pediatric oncology patients receiving RT. To our knowledge this study is one of the largest investigations of pediatric cancer patients receiving RT.

To exclude an effect of the changes of the medical environment and procedures during the 17 years of the study the influence of the treatment year was included in our multivariate analysis and was shown not to be significant. Therefore, the changes in RT instruments, better facilities or personnel changes in the time between February 1989 and January 2006 didn't influence the decreasing need of anesthesia over the time. Our anesthesia rate of $8.9 \%$ (of all RT courses), respectively $5.1 \%$ (of all RT fractions) in the intervention group is lower than in comparable patient groups in the literature, which show rates from $10.8 \%$ to $39.0 \%[1,4,5,18]$. Interestingly, nearly two thirds of patients younger than 5 years in group B (14 of 22 versus 15 of 45 in group A, Figure 1) were able to cooperate without anesthesia in the often frightening environment, whereas many centers routinely use general anesthesia in this age group [2,3]. One would expect RT to the head to be more frightening to the child than a more distant radiation field $[2,17]$. It is interesting that the psychoeducational intervention helped our patients to cooperate without anesthesia even in this difficult RT area. Surprisingly, our intervention was clearly more effective in girls than in boys. This might be attributable to the female nurse specialists applying the psychoeducational intervention. On that account, it would be important in the future to find more gender-specific strategies to cope with cancer. Another reason for this gender-related difference might be that girls are initially more afraid of RT than boys. It has previously been shown, that girls are more emotionally suffering from the diagnosis of cancer than boys [21]. Another explanation could be that girls in gen- 
eral are more motivated for such interventions than boys. Other factors such as cultural influences or the social situation of the family were not analyzed here.

In estimating the benefit of a psychoeducational support for RT, it is important not only to consider the age but also the site of irradiation, the planned positioning, and the gender of the patient. The need of intensive support is greater for example in a young girl expecting RT to the head or RT in a prone position than for an older boy with $\mathrm{RT}$ to a distant field or a supine positioning.

Clearly, the good outcome in our intervention group might also have been influenced by a more active participation of the parents, who gained a better understanding of the planned procedure and therefore were better able to assist their child during RT; this might be the most important benefit of our intervention in toddlers younger than 2 years. Furthermore, increased awareness by the medical team could also have influenced the decreased need for anesthesia in the supported group. Our psychoeducational intervention was a multimodal support package. This procedure not only facilitates a better understanding of the procedure, but also enables the child to share his situation with his parents and his play dolls [13].

Reducing the use of anesthesia offers several advantages to the child, their families, and the hospitals. One of them is the reduction in costs, as shown by several studies $[1,4,5]$. We were also able to show a reduction of costs by $36 \%$ due to our intervention. As the costs for the support per patient are so much lower compared to anesthesia, the only slight overall reduction of costs is astonishing. Psychoeducational support was offered to all patients undergoing RT regardless their age and RT planning details, however. Therefore many patients, especially those in the age group older than 10 years, received support although they might have been able to cooperate without anesthesia without being supported. In older patients, intervention is more helpful in reducing stress and anxiety levels and not the need of anesthesia, but this was not evaluated in our study. In order to further reduce costs the intervention could be offered only those patients who benefit most, which means for example girls or patients with RT in a prone position or RT to the head. But beside the cost reduction the immeasurable better understanding and comfort also of those patients with the assumed unnecessary support has to be kept in mind. Other studies were also able to show reduction of medical risks, of child distress, improved quality of care, and patient/family satisfaction by reducing the anesthesia rate [16]. However, these parameters were not included in our study, nor were treatment side effects as such, including fatigue and posttreatment nausea. The question as to whether a decreased use of anesthesia might improve the children's quality of life, or whether anesthesia might be superior to the traumatizing experience of RT, remains open.

\section{Conclusion}

In summary, our findings confirm the benefits of a psychoeducational intervention in preparing young pediatric cancer patients receiving radiotherapy. It has been shown in a large series of 244 consecutive oncology patients that psychoeducational intervention was able to significantly reduce the need of anesthesia during RT. Even young patients were able to cooperate for radiation without anesthesia, which resulted in a reduction of costs and an increased cooperation during RT.

\section{Competing interests}

The authors declare that they have no competing interests.

\section{Authors' contributions}

NB made substantial contributions to conception and design of the study and was mainly involved in drafting the manuscript. MAG had idea of this targeted psychoeducational intervention during radiotherapy and was also supervisor of this study. FKN was revising the manuscript critically. CL was responsible for the radio-oncological part of the study. RAA was involved in the interpretation of the results of the study and performed the statistical analysis. MAL was involved in the interpretation of the results and critically revised the manuscript. SH collected the data and helped to draft the manuscript. All authors read and approved the final manuscript.

\section{Acknowledgements}

The authors are grateful to E. Hardmeier and R. Heusser $f$, for performing the targeted psychoeducational intervention before and during radiotherapy. Special thanks to E. Zolcer for assisting with data collection and secretarial work.

\section{References}

I. Slifer KJ: A video system to help children cooperate with motion control for radiation treatment without sedation. I Pediatr Oncol Nurs 1996, I3(2):91-97.

2. Seiler G, De Vol E, Khafaga Y, Gregory B, Al-Shabanah M, Valmores A, Versteeg D, Ellis B, Mustafa MM, Gray A: Evaluation of the safety and efficacy of repeated sedations for the radiotherapy of young children with cancer: a prospective study of I033 consecutive sedations. Int J Radiat Oncol Biol Phys 200I, 49(3):771-783.

3. Lew CM, LaVally B: The role of stereotactic radiation therapy in the management of children with brain tumors. J Pediatr Oncol Nurs 1995, I 2(4):21 2-222.

4. Scott L, Langton F, O'Donoghue J: Minimising the use of sedation/ anaesthesia in young children receiving radiotherapy through an effective play preparation programme. Eur J Oncol Nurs 2002, 6(I): I5-22.

5. Klosky JL, Tyc VL, Srivastava DK, Tong X, Kronenberg M, Booker Z], de Armendi AJ, Merchant TE: Brief report: Evaluation of an interactive intervention designed to reduce pediatric distress during radiation therapy procedures. J Pediatr Psychol 2004, 29(8):621-626.

6. Zelikovsky N, Rodrigue JR, Gidycz CA, Davis MA: Cognitive behavioral and behavioral interventions help young children cope during a voiding cystourethrogram. J Pediatr Psychol 2000, 25(8):535-543. 
7. Liossi $C$, Hatira P: Clinical hypnosis versus cognitive behavioral training for pain management with pediatric cancer patients undergoing bone marrow aspirations. Int J Clin Exp Hypn 1999, 47(2): $104-116$.

8. Loewy J, Hallan C, Friedman E, Martinez C: Sleep/Sedation in children undergoing EEG testing: a comparison of chloral hydrate and music therapy. J Perianesth Nurs 2005, 20(5):323-33I.

9. Manne SL, Bakeman R, Jacobsen PB, Gorfinkle K, Redd WH: An analysis of a behavioral intervention for children undergoing venipuncture. Health Psychol 1994, 13(6):556-566.

10. Doverty $\mathrm{N}$ : Therapeutic use of play in hospital. Br J Nurs 1992, I(2):77, 79-8I.

II. Felt BT, Mollen E, Diaz S, Renaud E, Zeglis M, Wheatcroft G, Mendelow $D$ : Behavioral interventions reduce infant distress at immunization. Arch Pediatr Adolesc Med 2000, 154(7):719-724.

12. Pressdee $D$, May L, Eastman E, Grier D: The use of play therapy in the preparation of children undergoing MR imaging. Clin Radiol 1997, 52( I 2):945-947.

13. DuHamel KN, Redd WH, Vickberg SM: Behavioral interventions in the diagnosis, treatment and rehabilitation of children with cancer. Acta Oncol 1999, 38(6):719-734.

14. Hicks MD, Lavender R: Psychosocial practice trends in pediatric oncology. J Pediatr Oncol Nurs 200I, I8(4): I43-I53.

15. Janssen F: [Integration of psychosocial services into the management of the child with cancer]. Klin Padiatr 1989, 20I(4):346-349.

16. Patenaude $A F$, Kupst MJ: Psychosocial functioning in pediatric cancer. J Pediatr Psychol 2005, 30(I):9-27.

17. Schreck D, Glanzmann G, Sauter S, Niemeyer C: [Support in irradiation: a responsibility of the psychosocial team]. Klin Padiatr 1994, 206(4):303-305.

18. Slifer KJ, Bucholtz JD, Cataldo MD: Behavioral training of motion control in young children undergoing radiation treatment without sedation. J Pediatr Oncol Nurs 1994, I I (2):55-63.

19. Brigitte van den Heuvel CM Karien Kempen, Neel Konings, Gwenn Sieben, Jessica Bakker: Radio-Robby und sein Kampf gegen die bösen Krebszellen. Volume I. Ist edition. Edited by: (DLFH) KDLFAKVD. Bonn, Kinderkrebsstiftung und Deutsche Leukämie-Forschungshilfe - Aktion für krebskranke Kinder e.V. - Dachverband (DLFH) :49.

20. Michael Grotzer AS: Eugen und der freche Wicht. Volume I. Edited by: Michael Grotzer KZ. Zurich , Edition Moderne, Postfach 2253, CH-8022 Zürich, post@strapazin.ch; 2003.

21. Landolt MA, Vollrath M, Niggli FK, Gnehm HE, Sennhauser FH: Health-related quality of life in children with newly diagnosed cancer: a one year follow-up study. Health Qual Life Outcomes 2006, 4:63.

Publish with Bio Med Central and every scientist can read your work free of charge

"BioMed Central will be the most significant development for disseminating the results of biomedical research in our lifetime. "

Sir Paul Nurse, Cancer Research UK

Your research papers will be:

- available free of charge to the entire biomedical community

- peer reviewed and published immediately upon acceptance

- cited in PubMed and archived on PubMed Central

- yours - you keep the copyright
BioMedcentral 